\title{
A POLÍTICA DO FIM DO MUNDO: UMA LEITURA DISCURSIVA DE DOIS JOGOS DA SÉRIE "FAR CRY"
}

\author{
ISAAC COSTA $^{1}$ \\ Universidade Federal do Rio Grande do Sul \\ Rua Visconde de Paranaguá, 102, bairro Centro, Rio Grande, RS, 96203-900 -Brasil. \\ isaac.costa@tuta.io
}

\begin{abstract}
Resumo: Inserido na vertente materialista da Análise de Discurso, este texto propõe uma leitura crítica de Far Cry 5 em contraponto com sua continuação direta, Far Cry New Dawn. No percurso analítico, objetiva-se explicitar a maneira como esses dois jogos retratam um momento específico da conjuntura social atual, qual seja, a crise do capitalismo liberal e alguns de seus correlatos: as reações políticas totalitárias; a alienação religiosa de um fundamentalismo radical; as consequências de uma guerra nuclear e de orientação biogenética; os problemas vindouros de escassez de matériaprima, comida e água; além do crescimento das divisões e das exclusões sociais.
\end{abstract}

Palavras-chave: Alienação religiosa; Ideologia; Fundamentalismo; Totalitarismo.

\begin{abstract}
Inserted in the Discourse Analysis led by Michel Pêcheux, this text proposes a critical analysis of two games: Far Cry 5 and its direct continuation, Far Cry New Dawn. The objective is to make explicit how these games portray a specific moment in the current social context: the crisis of liberal capitalism and some of its correlates, like the totalitarian political reactions; the religious alienation of the radical fundamentalism; the consequences of a nuclear and biogenetic war; the coming problems of scarcity of materials, food, and water; and, finally, the constant growth of divisions and social exclusions.

Keywords: Religious alienation; Ideology; Fundamentalism; Totalitarianism.
\end{abstract}

\section{INTRODUÇÃO}

De início, penso ser importante situar aqui um conjunto de dados históricos e produtos culturais que, por mais que aparentem estar desconexos, integram um mesmo continuum das condições de produção do discurso que sustenta a prática do fundamentalismo religioso. É tomando como base esse fundamentalismo e seus correlatos, o totalitarismo e a alienação religiosa, que procuro investigar a maneira

\footnotetext{
${ }^{1}$ Doutorando em Estudos da Linguagem pela Universidade Federal do Rio Grande do Sul, laureado em Licenciatura em Letras pela UFRPE, e mestre em Linguística pela Universidade Federal de Pernambuco (UFPE). ORCID: http://orcid.org/0000-0002-4635-2824
} 
como ocorre o contato (ou, mais especificamente, o deslizar de sentidos) entre o conservadorismo religioso e a ideologia que rege o ultraliberalismo político. A metodologia toma como princípio os procedimentos fornecidos pela Análise de Discurso pecheutiana, e realiza a leitura discursiva de dois títulos da franquia de jogos Far Cry, quais sejam: Far Cry 5 e Far Cry New Dawn. Esses são jogos de ação em primeira pessoa, um gênero de games em que o indivíduo-jogador é injungido a assumir a posição de sujeito-personagem no interior da narrativa fornecida. Nesse ambiente, as missões a serem executadas seguem uma lógica interna, explicada para o jogador em cenas animadas em que as personagens antagonistas dialogam com o sujeitopersonagem. A construção dessas personagens e certas passagens das conversas que conduzem (marcadas com aspas ao longo do texto), constituem a matéria mais concreta sobre a qual me debruço nesta análise, que se inicia pela explanação do caso TateLaBianca e a figura de Charles Manson, notório fanático religioso estadunidense.

Em 1968, quando foi lançada, ninguém poderia imaginar que a enérgica canção Helter Skelter, do White Album dos Beatles, assumiria o sentido que lhe conferiu Charles Manson² durante o depoimento que concedeu à Corte da Califórnia, ao ser julgado pelos múltiplos assassinatos cometidos pelos membros do grupo que ele liderava e identificava como família. Para Manson, a canção funcionava como chamamento para uma guerra étnica, uma espécie de indício material de que o barulho das lutas segregativas na sociedade americana finalmente tornava-se audível. O som que se apresentava agora anunciava que os negros ganhariam uma disputa contra os brancos, mas que não estariam aptos a assumir o controle do Estado. Nesse cenário, seria ele, Charles, o único que conseguiria presidir a nação e impedir que o caos fosse instaurado pelo grupo adversário. O plano de Manson consistia na execução de pessoas brancas, ricas e famosas, a quintessência do que seria considerado o modelo de cidadão bemsucedido na década de 1960, seguida da culpabilização dos negros e dos pobres por esses homicídios, o que figuraria como vingança pela opressão social. Uma das vítimas desse plano, a atriz Sharon Tate, então grávida de oito meses, daria nome ao caso que se destacou como crime hediondo em 1969: o homicídio brutal de cinco pessoas na Cielo Drive, 10050, cujo sangue foi usado para desenhar nas paredes do local as palavras "pig" (porco) e "Helter Skelter".

Depois da prisão de Manson em 1971 pelo caso Tate-LaBianca, a história estadunidense das décadas subsequentes foi marcada pela ação mais ou menos coordenada (mas não menos catastrófica) de chacinas organizadas por líderes de seitas religiosas, semelhantes às cometidas pela família Manson. Aí se enquadram, por exemplo, a exploração e morte por envenenamento dos mais de 900 fiéis de Jim Jones em "Jonestown"3 ; assim como o conflito entre as forças armadas e o "Ramo Davidiano"

\footnotetext{
${ }^{2}$ Cf. VIGGIANO, Giuliana. Quem foi Charles Manson, o líder da seita que aterrorizou os EUA em 1969. Revista Galileu, 30 jul. 2019. Disponível em: http://glo.bo/3oxKFXD. Acesso em jan. 2021.

${ }^{3}$ Uma espécie de terra santa organizada por Jim Jones sob a ótica de um ideal socialista deturpado. Construída na Guiana, Jonestown foi um pequeno vilarejo que abrigou cerca de 900 pessoas. Trabalhando em comunidade e por seu próprio sustento, os habitantes não recebiam salário nem tinham acesso a qualquer tipo de aparelho eletrônico, já que o dinheiro e a mercadoria eram associados ao "mundo exterior", corrupto e selvagem. Sem contato com seus familiares e com o meio externo, situados em um país no qual eram estrangeiros, os fiéis eram submetidos a cargas excessivas de trabalho e a abusos físicos, sobretudo sexuais. Depois de ordenar o assassinato do congressista Leo Ryan, que havia ido à Guiana investigar as condições de vida em Jonestwon, Jim Jones inferiu ser inevitável uma intervenção do Estado americano na comunidade. Sob essas circunstâncias, orquestrou um "suicídio revolucionário
} 
guiado por David Koresh, em Waco. A dinâmica que pode ser observada em todos esses casos é uma espécie de devaneio coletivo em que um grupo de pessoas se aliena e passa a atribuir características divinas a um dirigente específico e carismático, um profeta responsável por guiar seu rebanho à salvação. Enraizadas no imaginário da população norte-americana, as imagens do psicótico líder do culto e dos seus fanáticos seguidores em seitas religiosas são recuperadas por diversas obras artísticas de grande impacto cultural, a exemplo de filmes como Helter Skelter de John Gray (2004) e Once Upon a Time in Hollywood de Quentin Tarantino (2019). Além destes, destacam-se a produção de diversos vídeo-documentários e minisséries com cenas reais ou fabricadas envolvendo os líderes de culto, como o fazem Mindhunter de David Fincher e Jim Davidson (2018); American Horror Story: Cult de Ryan Murphy (2017); e Unbreakable Kimmy Schmidt de Tina Fey e Robert Carlock (2015).

Esse tipo de cenário também serve como pano de fundo para o desenvolvimento do quinto título da franquia Far Cry, segundo jogo mais rentável da Ubisoft e um dos games de tiro em primeira pessoa mais bem avaliados pelo Metacritic. Em 2018, cinquenta anos depois do lançamento do White Album, Far Cry 5 toma como antagonista Joseph Seed, "O Pai", líder cristão do Projeto Portão do Éden (do original Project at Eden's Gate), destinado a salvar os fiéis de um iminente Colapso da humanidade. Joseph conta com a ajuda de seus irmãos, os três arautos, para selecionar, converter e guiar espiritualmente seu rebanho, que começa a ser reunido no condado fictício de Hope County, Montana. A ideia é a de que o jogador, recentemente recrutado pelo xerife de Hope County, ofereça resistência ao culto apocalíptico que está militarmente armado. A expansão que corresponde à continuação de Far Cry 5, Far Cry: New Dawn, de 2019, explora a maneira como o condado se encontra 17 anos após uma explosão nuclear. Na narrativa desenvolvida, essa explosão corresponde ao que Joseph identificava como o apocalíptico Colapso, que deixaria vivos apenas aqueles guiados por ele.

A controvérsia que girou em torno de Far Cry 5 há época de seu lançamento dizia respeito a uma série de eventos em que era possível perceber as consequências de um extremismo religioso que, de alguma forma, conectava-se ao conservadorismo cultural e ao radicalismo de um direcionamento político direitista cada vez mais acentuado. O mais notável desses acontecimentos, a posse de Donald Trump, em 2017, alia-se, assim, com a validação de um discurso nacionalista que exclui, em nome da identidade do povo americano, qualquer potencial alteridade geográfica, étnica, religiosa, sexual, político-ideológica etc. $\mathrm{Na}$ mesma medida, destacam-se também ataques aos veículos de impressa tradicionais, alinhamento com bases religiosas radicais, disseminação de informações falsas, posturas antiambientalistas etc. Daí resulta o pronunciamento acerca da construção do muro entre os EUA e o México; o aumento da relevância política dos movimentos contra os direitos das pessoas LGBTQIA+, das mulheres e dos negros; e a pretensa revalidação ou o retorno a um estado de coisas que supostamente faziam com que a América fosse tão grande e tão rica em outros tempos irrecuperáveis. O mesmo cenário político ultraliberal e ultraconservador que se apresenta fortemente nos Estados Unidos em 2017 pode ser observado em outros países cujas figuras em liderança, ou as que orbitam em torno dela,

em massa" de todos os seus fiéis por ingestão de cianeto. No fim, os que se recusaram a ser voluntariamente envenenados foram perfurados com agulhas contendo cianeto ou alvejados por balas disparadas pela guarda pessoal de Jones, encontrado morto por um tiro na cabeça. 
são tão problemáticas quanto a de Donald Trump. Aí se enquadram, por exemplo, Jair Bolsonaro no Brasil; Viktor Orbán na Hungria; Matteo Salvini na Itália; e Rodrigo Duterte nas Filipinas, para citar alguns.

Durante as entrevistas que concederam à mídia, em especial naquela que realizou Kevin Dunsmore para o Hardcore Gamer, os desenvolvedores de Far Cry 5 foram indagados se esta época de agitação política era a melhor possível para o lançamento de um jogo que toca em questões tão sensíveis e que envolve explicitamente o cenário norte-americano; diferente de outros títulos da franquia, como Far Cry 4, que se passa nos Himalaias, e Far Cry Primal, ambientado na idade da Pedra. Em resposta, os diretores do jogo afirmaram o óbvio: não tínhamos como prever o que aconteceria com os Estados Unidos quando começamos a desenvolver o game ${ }^{4}$. Certamente, é forçoso admitir que um produto cultural desse tipo seja capaz de antecipar ações sóciohistóricas que são, em última instância, determinadas por fatores de ordem econômica. De outro lado ainda, de que forma exatamente o conteúdo do jogo pode assumir uma dimensão crítica ao radicalismo político de uma direita ultraliberal, se se propõe a discutir apenas um aspecto social muito preciso sobre o fundamentalismo religioso levado ao seu limite? Por mais críveis que possam parecer esses dois argumentos que servem de base para o afastamento de Far Cry 5 de uma dimensão iminentemente política; a constatação de que, por um lado, é "óbvio que não é possível prever o futuro", e, de outro, que "o fundamentalismo é diferente do ultraliberalismo", não se alia, senão, aos processos ideológicos de a) produção do efeito de evidência e de b) divisão paradoxal dos objetos na sua totalidade.

O esforço para tornar apolítico ou "livre de ideologia" um produto cultural gera um tipo de reforço expresso linguisticamente em que é possível perceber, por intermédio do ato de defesa, determinados mecanismos de produção do sentido; lugar mesmo em que se entrelaçam língua e história, inconsciente e ideologia. Entendamos bem: o que faz com que este seja um jogo envolto por questões políticas e, assim, terminantemente afundado em ideologia, não é necessariamente a defesa que afirma não conseguir antecipar um cenário social preciso, mas, sim, como o formulou Eni Orlandi, em Encontros na análise de discurso, de 2019, o fato de que "toda história intelectual começa muito antes de começar" $(2019$, p. 21$)$. O ponto observável nessa cadeia não corresponde ao lançamento de Far Cry 5, mas às condições materiais que lhe são anteriores e que asseguraram a sua fabricação em primeiro lugar.

Nessas condições estão inclusas tanto as paulatinas mutações sociais que manifestam o descontentamento com um certo estado de coisas no capitalismo liberal, quanto o processo de reprodução dos sentidos com os quais o jogo visa corroborar. Em si, o pronunciamento dos criadores não é o responsável pelo contato da obra com a ideologia política. Ele meramente integra uma rede de referentes em contato que denunciam os pontos em que é possível observar a forma como as determinações de ordem sócio-histórica interferem na produção do sentido. Esses pontos remetem à superfície linguística em que se manifestam os efeitos (porque ilusórios) de uma constituição a-histórica do sentido. A afirmação que se apresenta, "é evidente que este sentido não se conecta ao cenário social em que se insere", opera dois movimentos: primeiro, aponta uma causa metafísica para o dizer (o sentido surge por ele mesmo); e

\footnotetext{
${ }^{4}$ Tradução livre do original "The simple truth is that we didn't know what was going to happen in America when we began development” (DUNSMORE, 2017).
} 
depois, encobre o fato de que a constituição sentido, sempre em contato com a constituição do sujeito, "resulta de um processo" (PÊCHEUX, 2014, p. 143).

Inserido na vertente materialista da Análise de Discurso, este texto procura investigar estes pontos precisos, aparentemente dispersos, em que a ordem social irrompe na estrutura regular da língua, propiciando o surgimento do sentido. Para tanto, proponho uma leitura crítica de Far Cry 5 em contraponto com sua continuação direta, Far Cry New Dawn. Nesse percurso, objetivo explicitar a maneira como esses jogos retratam um momento específico da conjuntura social atual, qual seja: a crise do capitalismo liberal e os seus correlatos - a crise ecológica; as consequências de uma guerra nuclear e de orientação biogenética; os problemas vindouros de escassez de matéria-prima, comida e água; além do crescimento das divisões e das exclusões sociais. Interessa, ainda, compreender como se dão os vínculos entre as matrizes de sentido do conservadorismo religioso e do ultraliberalismo político, procurando cercear o discurso que as atravessa e lhes possibilita a existência. O método de investigação adotado é centrado no levantamento bibliográfico e na análise discursiva da narrativa e de sentenças específicas extraídas dos dois jogos, atentando, assim, para a identificação das condições de produção que sustentam essas materialidades.

A percepção crítica adotada pelo estudo tem como finalidade tornar audíveis os ruídos de fundo das incessantes disputas assimétricas travadas entre as classes, o que confere densidade ao significado. Esse fundo de desordem que um imaginário específico tenta homogeneizar e silenciar corresponde a uma série de processos ideológicos complexos e intrincados uns nos outros. Para me ater à desconstrução destas imagens, cristalizadas, por exemplo, em reduções, inversões ou generalizações grosseiras (o sentido geral que se atribuí ao "óbvio" como sendo isso que é transparente, unívoco; ou, ainda, reduções cínicas e simplistas, como, por exemplo, tratar de uma pandemia como "gripezinha", rotular a produção de ciência nas universidades públicas como "balbúrdia"; falar do sexo feminino como "fraquejada"; enfim, eleger um Helter Skelter qualquer ${ }^{5}$ ), tomo como base teórica as concepções pecheutianas acerca da opacidade da língua e do contato entre esta, a ideologia e o discurso, num arranjo que comporta, ainda, uma dimensão profundamente inconsciente. Além de Pêcheux, recorro às reflexões de Žižek sobre a realidade da conjunção entre o político e o teológico, sobretudo na alegoria que o autor tece com o apocalipse em Vivendo no fim dos tempos, de 2012, ao tentar projetar as consequências do fim do capitalismo (do mundo como o conhecemos). Os arautos de Joseph (Faith, Jacob e Jhon) e personagens de Far Cry New Dawn como Carmina Ray e Ethan Seed, servirão de índice para discussão dos sentidos que sustentam as práticas discursivas suscitadas, a saber: a alienação religiosa, o totalitarismo e a divisão paradoxal dos objetos discursivos. O primeiro desses tópicos, reservado à Faith e Jacob, é explorado a seguir.

\section{A RESPEITO DA ALIENAÇÃO RELIGIOSA: FAITH E JACOB SEED}

Vimos, no início deste trabalho, que o antagonista de Far Cry 5 (doravante FC5), Joseph Seed, designa a cada um dos arautos tarefas específicas com relação ao

\footnotetext{
5 Aqui faço referência a expressões utilizadas pelo Presidente da República e por membros de seu governo em pronunciamentos oficias ou falas públicas. Sobre esses termos, Cf. FREIRE (2020) e BBC NEWS (2020).
} 
tratamento de seu rebanho, a quem a resistência chama de "edenetes"6. Sua irmã mais nova, Faith Seed, coordena um segmento especial de escolhidos, conhecidos como "anjos". Diferente do resto dos edenetes, o comportamento dos anjos se assemelha ao de um zumbi, com passos lentos e movimentos descoordenados. Vestem roupas inteiramente brancas e sempre aparecem com máscaras no rosto por onde é possível perceber a vaporização constante de uma fumaça esverdeada, a "benção". Na narrativa do jogo, a benção é uma espécie de droga alucinógena utilizada por Faith para converter e manipular os seguidores a partir da fragilização físico-emocional e da dependência química. A alusão ao uso de entorpecentes não é necessariamente novidade nos títulos da franquia, que já havia explorado essa temática de maneira mais tímida em Far Cry 3 e em Far Cry Primal. Em 2014, no enredo de Far Cry 4, as drogas recebem um novo contorno ao se discutir a produção e a comercialização de opioides como alternativa para ascensão econômica de Kyrat, país fictício em que se ambienta Far Cry 4. FC5, entretanto, explora com maior veemência as consequências do abuso de substâncias desse tipo, conferindo destaque especial ao comportamento quase irracional de explosões contingentes de raiva dos anjos, e à indução do suicídio do agente federal Cameron Burke.

FC5 afirma de outra forma a questão levantada pela mídia durante a cobertura do caso Tate-LaBianca: a de que os alucinógenos desempenharam papel central nos assassinatos cometidos pelos membros da família Manson, alterando seu estado de consciência. De outro ângulo, mas visando o mesmo ponto, o que o jogo faz é apontar que os entorpecentes não servem senão como instrumentos para manutenção de um estado de dominação que lhes é maior e anterior. Não raro, as aparições de Faith (cujas vestes e o semblante sempre risonho assemelham-se aqueles apresentados pelas mulheres da família Manson) incluem a figura do Pai, a quem ela remete como salvador. Assim, uma coisa é a alteração mais ou menos programada da consciência que as drogas possibilitam, a criação efetiva dos "anjos"; outra coisa é aliar essa alteração com o condicionamento inconsciente de um modo específico de pensar e agir, a exemplo do alinhamento desses anjos com os ideais do Portão do Éden. Em outros termos, não se comete uma chacina do tipo daquela orquestrada por Manson unicamente por estar drogado; muito provavelmente, aquele grupo de indivíduos alienados de si representavam sujeitos superidentificados com o discurso de Manson, a "alma" que lhes animava o corpo. As alterações químicas dos estados de juízo cooperam com (mas não determinam em última instância) um processo que é iminentemente ideológico.

Sobretudo, o papel que Faith ${ }^{7}$ desempenha é o de ofertar e garantir uma injunção à fé, ou seja, ao amor incondicional pelo Pai. Essa função é particularmente acentuada quando Faith enuncia que "o caminho para o Éden é claro para aqueles que têm fé". A primeira chave interpretativa de uma sentença deste tipo é a de que o caminho da salvação só é reconhecido ao se ter fé. Para tanto, não é suficiente demonstrar apenas admiração ou devoção, mas, sim, alcançar a incondicionalidade do ato de amar o Pai: não por suas particularidades, mas com todas as suas possíveis imperfeições, amando-o pelo que é, e não pelo que faz. Interessa ainda destacar que, como bem o pontuou Žižek,

\footnotetext{
${ }^{6}$ Em Inglês, os edenetes são referidos como "peg", no singular, ou "peggies", no plural; acrônimo de "project at eden's gate". A sonoridade e a grafia do termo são próximas das palavras "pig" e "piggie", respectivamente "porco" e "porquinho" em Português. "Pig" também estava entre os termos escritos com sangue nas paredes da mansão da Cielo Drive, 10050.

${ }^{7}$ Cujo nome é o correspondente em inglês da palavra "fé".
} 
"o amor cristão é a paixão violenta de criar uma diferença, uma lacuna na ordem do ser, de privilegiar e elevar um objeto à custa dos outros" (ŽIŽEK, 2012, p. 110-111), ao que se associa a ideia de que amar um elemento de um dado conjunto pressupõe, pelo menos, uma indiferença dirigida aos demais integrantes desse arranjo.

No limite, amar incondicionalmente pressupõe odiar os outros em detrimento do um, como se afirma em Lucas 14, 26: "se alguém vem a mim e não odeia seu próprio pai e mãe, mulher, filhos, irmãos, irmãs e até a própria vida não pode ser meu discípulo". Não se deve, entretanto, assumir que o amor extremo encontra no ódio o seu extremo oposto. O ódio aí aludido não funciona como espelho dialético do amor, mas como resposta à ação de qualquer vinculação cultural que possa perturbar a relação entre o homem e Deus. As relações de parentesco figuram metaforicamente como as instituições criadas pela lei dos homens. O mesmo tipo de associação pode ser realizado entre pares semânticos como a paz e a espada, em que o divino funciona como aquilo que perturba a estabilidade de um certo aspecto estático das coisas: "não julgueis que vim trazer paz à Terra. Vim trazer não a paz, mas a espada" (Mateus, 10-34). Por este viés, uma interpretação que não leve em consideração as nuances desses sentidos, pode facilmente incorrer em perversões que tentem justificar e/ou incitar o ódio ao próximo, sempre em nome de um amor maior. É exatamente isto que faz Faith, ao dizer, por exemplo, "viva pela espada", sentença que comporta paráfrases do tipo "viva pela luta"; nesse esquema, "luta", "espada" e "batalha" estão mesma esteira de sentido: a da guerra "santa" contra o outro infiel, contra quem deve ser erguida a espada. Desse modo, a produção e a distribuição da Benção por Faith são atos relevantes, mas periféricos ao mecanismo de injunção ideológica estruturante.

Ao pensar sobre quais foram os regimes políticos que proclamaram abertamente o amor ao seu líder não é difícil lembrarmo-nos de sistemas totalitários, como o nortecoreano, por exemplo. Em casos como o da Coreia, o amor encontra no terror absoluto seu complemento imediato: a misericórdia. $\mathrm{O}$ fato de esse líder ser capaz de destruir a qualquer tempo os seus súditos e, mesmo assim, não o fazer, seria a prova do seu amor por eles. Terror e amor integram uma mesma estrutura totalitária que comporta tanto a misericórdia e a compaixão, quanto o ódio e a espada. Desta forma, considerar uma totalidade não significa concebê-la como um Todo harmonioso, mas perceber as incoerências e antagonismos em relação de afetação num dado sistema. A possibilidade de compreensão de Faith como arauto amoroso é sustentada pela sua contraparte aterrorizante, que, nesse arranjo, encontra expressão expoente em Jacob Seed, o arauto responsável pela segurança do culto. Veterano da guerra do Iraque, Jacob objetiva "preparar o rebanho por meio da dor" e, para tanto, submete os habitantes locais a eventos de "separação". A ideia é sequestrar as pessoas, tortura-las e trancá-las juntas em um espaço cheio de armas. Uma única pessoa escapa viva do confinamento: aquela que conseguir ser mais forte eliminando os fracos. Os escolhidos são selecionados para juntar-se a Jacob e integrar a força de segurança do Portão do Éden. A violência abertamente declarada de Jacob é justificada como uma violência operada em favor de uma "limpeza física e espiritual". Essa inversão garante que a agressão objetiva se fundamente e justifique pelo ato de fé - a sensação da violência brutal é confirmada por outra injunção: é preciso ter força para cumprir a profecia divina e defender-se contra os ataques iminentes dos infiéis. 
Em parte, essa injunção à fé e à violência são componentes integrantes de um mesmo movimento, que corresponde ao que descreve a teoria da alienação religiosa de Feuerbach, base para as reformulações críticas sobre a ideologia operadas por Marx e Engels n'A Ideologia Alemã, de 1845-1846. Para Feuerbach, sobretudo na religião, o homem concebe um "outro" (do latim alium) dotado de virtudes superlativas, em quem reside a responsabilidade pela criação do mundo. $\mathrm{O}$ processo de alienação ocorre quando este alium passa a ser encarado como o criador do homem, e não o contrário; momento mesmo em que se pontua a assunção das figuras divinas como seres separados dos homens, com poder sobre eles e cuja existência é explicada em si mesma. Esse tipo de transferência explica o mecanismo pelo qual a figura de Joseph passa a ser concebida como divina. Apropriando-se desse conceito, mas de um ponto de vista social, Marx e Engels consideram que $o$ resultado prático da alienação faz referência ao desconhecimento das ações sociopolíticas, isto é, da práxis que orienta as condições materiais, que são historicamente determinadas.

Assim, os dizeres sobre a revelação, “a Voz" que Joseph afirmava ter ouvido e que o identifica como único escolhido por Deus para salvar a humanidade, encobrem tanto uma necessidade de afirmação quanto o fato de que o meio religioso foi o único espaço em que esse sujeito obteve alguma forma de validação social. Outrora, nos seus sucessivos empregos temporários, como limpador de rua, por exemplo, Joseph era assombrado pelo fantasma de uma gritante mediocridade. Esse lugar de irrelevância figura como oposto simétrico da ideia do cidadão que persegue o impossível de um American Dream. A realidade projetada nesse sonho é o sucesso financeiro, e sua impossibilidade de realização se alia à determinação de uma estruturação piramidal que orienta a base a reproduzir a força produtiva. Para Althusser (1996), os níveis mais elevados dessa pirâmide, aqueles que efetivamente detêm os meios de produção, asseguram materialmente o processo de reprodução dos meios de produção pelo exercício do poder nos aparelhos ideológicos e repressivos de Estado. Inserido em uma estrutura social desse tipo, não há possibilidade concreta de ascensão social para Joseph senão por operações que visem instituir para ele um lugar dominante no interior de um desses aparelhos, notadamente, o religioso. A ambição de Joseph é, sobretudo, a de corresponder ao próprio poder estatal - de ser ele mesmo a figura central dessa totalidade e assumir o controle da máquina que engoliu seu sonho de oprimir.

Nesse caso, a alienação religiosa corresponde a dois movimentos baseados numa mesma ilusão: o primeiro, conduzido por Joseph, busca separá-lo da realidade concreta projetando suas ações para fora do campo da determinação sócio-econômica. $\mathrm{O}$ segundo, agenciado pelos seus fiéis, alça Joseph à posição de Pai, deixando de identifica-lo como indivíduo assujeitado a um complexo sistema de estruturação social baseado na divisão social do trabalho e identificando-o com um objeto superior, alheio à sobredeterminação. No fundo, esse jogo de projeções reflete apenas o anseio desses sujeitos de alcançarem um plano (nesse caso, espiritual) em que as suas individualidades (bom comportamento, caráter, índole) serão reconhecidas e celebradas. O que é apagado nesse processo - o lugar social de Joseph, seus fracassos, frustrações e seu desejo por reconhecimento e prestígio social - corresponde à realidade das condições de produção de um discurso centrado na exaltação desmedida e eufórica de uma figura meramente humana, um sujeito que, como o dirá Pêcheux (2014), "esquece" que não é o produtor do sentido e que não controla o que diz. 
Ainda assim, a cisão desse sujeito ideologicamente interpelado, sua submissão a um sistema inconsciente, garante a existência de ações repetidas que buscam inscrever o non-sens na estrutura regular do sentido. Essa é a fórmula segundo a qual os dizeres "negados", isto é, aqueles que se oferecem à consciência e por ela são barrados, produzem vestígios materiais da falha de sua simbolização, como o lapso, o contradito e o ato falho, por exemplo. Nesses termos, de um lado, existe uma pretensa alteridade no dizer de Joseph, o fato de ele não dispor de uma verdade própria, mas, sim, ser mero instrumento da vontade de Deus, que lhe permitiu enxergar "o que estava por vir e agir, liderar porque a sociedade está esfacelada [sendo] o único caminho adiante é retornar a que um dia já fomos: inocentes e puros, seguros e protegidos em nosso jardim". De outro lado, após a efetivação do Colapso, o tom é radicalmente alterado para uma subjetividade que se afirma agora como detentora da verdade: "sabe o que significa? Que os políticos foram silenciados, que as corporações foram apagadas, que o mundo foi purificado pelo fogo sagrado de Deus, e, o mais importante, significa que eu estava certo". Na fala de Joseph, se, antes, era Deus quem o permitia enxergar, agora, é Joseph quem planeja ocupar o lugar de Deus e fazer com que o jogador enxergue; o que pode ser percebido, nesse exemplo, desde a marcação do sujeito como singular "eu estava certo", em oposição ao plural "fomos" na primeira sentença.

Dessa forma, aquilo que não poderia ser dito e que foi desprezado pela consciência, o desejo inconsciente desse sujeito que almeja reconhecimento como líder absoluto e o seu desprezo pelo sistema econômico que o marginalizou, irrompe na estrutura do sentido como contradito e faz com que Joseph reitere o seu lugar de senhor, de grande Pai. De forma semelhante ao que operou Jim Jones há época da construção de Jonestown, Joseph também apresenta indícios de sua rejeição pelo sistema econômico vigente e o consequente flerte com outros tipos de regimes políticos de um socialismo deturpado. A relação de Joseph com o trabalho, a comunidade e a propriedade privada é mediada por seu irmão John, o segundo dos arautos do Portão do Éden, cujas práticas passamos a explorar a partir deste ponto.

\section{SOBRE O TOTALITARISMO: JOHN SEED E CARMINA RYE}

Se, no paralelo que foi tracejado no tópico anterior, Faith atuava na manutenção do aparelho religioso e Jacob representava as forças do aparelho repressivo; como advogado do Portão do Éden, John desempenha papel decisivo para o exercício do poder no aparelho jurídico. Na descrição oficial do jogo no site de FC5, John é apresentado como sendo aquele que "garante recursos vitais à sobrevivência do culto, seja isso uma casa ou uma pessoa", funcionando, assim, como a figura responsável pela arrecadação de fundos e aquisição das propriedades da seita: residências; igrejas; armas; rodoviárias; aeroportos; complexos; armazéns; e veículos terrestres e aéreos. Na prática, o fato de Hope County corresponder, em grande parte, ao acumulado das propriedades do Portão do Éden, justifica legalmente a liberdade de ação dos membros da seita. Salvaguardadas as devidas proporções, em FC5, John é a epítome da reprodução das condições materiais de existência do culto.

John sustenta a possibilidade de Joseph assumir um sentido de comunidade igualitária e autossustentável para o Portão de Éden. Num espaço deste tipo, a exemplo de Jonestwon, os membros podem trabalhar apenas pelo alimento da família, que perde a conotação local e passa a designar o próprio culto. A promessa é a de que a exploração 
da força de trabalho e a busca pelo engrandecimento pessoal, práticas particulares ao sistema capitalista liberal, cedam lugar ao trabalho comunitário e à alteridade absoluta, regida por um forte senso de solidariedade. Teoricamente, nesses meios não haveria comércio ou circulação de dinheiro, estando extinta a produção e venda de qualquer mercadoria. Dito de outra forma, os indícios materiais da dominação e da exploração do trabalhador são estranhos aos edenetes porque John legalmente detém as propriedades da seita e gerencia a distribuição de riqueza, sob o aval de fazer "isso sempre em favor do grupo, não do indivíduo".

Não por acaso, a partir do ritual de "expiação", uma espécie de confissão dos pecados acompanhada da escarificação (por faca ou outra lâmina) do nome pelo qual estes são identificados (ira, gula, luxúria etc.) no corpo dos fiéis, John ataca diretamente a base sobre a qual se funda o senso de privacidade, tornando públicas as práticas "incorretas" cometidas em regime privado. Atacar a esfera privada é um passo fundamental para o processo de deturpação da ideia de posse, inclusive sobre o próprio corpo. Nesse sentido, pela doutrina imputada no ato de expiação, os corpos em comuna se entrelaçam em um único corpo e constituem, eles mesmos, a via direta para um despertar espiritual guiado pelo Pai. A proposta de John, dirigida ao jogador, "seja o seu pecado. Ele guia você, seus pensamentos, suas ações. Seu pecado é a ira. Torne-se a ira, deixe-a preencher o seu corpo e consumir sua alma, porque no fim você ainda será vazio", se concentra em incutir a ideia de que o sujeito, desde sempre fadado à danação, "é o que comete", coincide com o próprio pecado, e por isso se torna uma forma de existência desubstancializada e vazia. Ao operar essa despercepção, o sujeito se encontra reduzido a uma entidade espectral que é, ao mesmo tempo, invisível para os outros, mas observável para o Pai, que lança sobre o sujeito o olhar misericordioso de identificação e reconhecimento.

Essa mesma despercepção cerceia a fantasia utópica de FC5 que pressupõe para o Portão do Éden uma comunidade harmoniosa, isenta das disfunções que cerceiam a sociedade "pós-moderna". Nesse novo espaço, onde inexiste o homem moderno, cada um saberá organicamente a sua função e o seu lugar no mundo, operando em conjunto para a manutenção de uma sociedade que se propõe para "além-da-cultura", em sentido reverso: dentro do estado de natureza, refletido no modus operandi das abelhas em colmeia, por exemplo, em que a rainha corresponde ao próprio Joseph. A ilusão retroativa que situa o Éden como ponto zero da comunidade harmônica encobre o fato de que foi a própria queda, ou seja, a expulsão do homem do paraíso, o que tornou possível conceber a ideia de paraíso. O que a história repete nessa cadeia não é exatamente a tentativa de reconstrução do Jardim Sagrado (o que o Éden é), mas a sua queda (o que ele foi), que efetivamente continua a existir. Sobretudo em Far Cry New Dawn é possível perceber que o que se sabe sobre o Éden é que ele nos foi negado como tal, o paraíso só continua a existir como margem de impossível, de modo que toda tentativa de alcança-lo estaria fadada ao fracasso desde o princípio. Essa ideia se verifica, por exemplo, no começo da narrativa de New Dawn, quando Carmina Rye explica ao jogador como a humanidade conseguiu sobreviver depois do Colapso.

Em uma das missões principais de FC5, o jogador auxilia o pai de Carmina, Nick Rye, integrante das armas de aluguel (gun for hire), a levar sua esposa, que está prestes a dar à luz, até a casa da parteira de Hope County. Carmina, filha de Nick, nasce no mesmo ano em que ocorre o Colapso de FC5 e sobrevive abrigada em um bunker 
junto com a sua família e outros membros da resistência. Passado um rigoroso tempo de chuvas ácidas e fortes vendavais, 17 anos após as explosões nucleares, os humanos restantes começam a reconstruir a sociedade em que viviam. $O$ cenário do jogo, diferente do tom acinzentado que costumam apresentar as produções de narrativa pósapocalíptica, é de um colorido vívido, quase neon. Em Far Cry New Dawn, a natureza se ajustou à desordem causada pelas explosões e tomou posse das construções humanas, engolindo os prédios com arbustos floridos, cheios de animais cujas cores e formas foram afetadas pela radiação. Carmina descreve o espaço exterior como a coisa mais bonita que ela já viu, enquanto seus pais lamentam pela perda da sociedade como eles a conheciam.

Durante essa explicação fornecida por Camina também são apresentadas as antagonistas da nova história, as gêmeas Mickey e Lou, que comandam o grupo de Salteadores. Ao estilo de Mad Max, de James McCausland e George Miller, os salteadores constroem carros, armas e abrigos com os restos de matéria-prima e de etanol que conseguem encontrar pelo condado. A identidade visual dessas personagens e a trilha sonora que acompanha as cenas de história em que aparecem, mesclam elementos do grafite com a cultura da pichação, hip-hop, rap e trap music. A mistura dessas referências culturais modernas, objetiva promover a simpatia do jogador pelo grupo de salteadores. Como em outros títulos da franquia, a ideia não é meramente apontar um vilão radicalmente diferente, que pelo conjunto de seus atos perversos deve ser eliminado a qualquer custo; mas, sim, provocar algum tipo de reflexão no jogador, aproximando os divergentes e humanizando as figuras antagônicas. Assim que Mickey e Lou descobrem sobre a prosperidade do grupo de Carmina em Prosperity, os salteadores saqueiam os recursos coletados pela resistência, destruindo o vilarejo. É neste ponto que Carmina busca pela ajuda de um grupo de especialistas em sobrevivência e desenvolvimento, do qual o jogador é membro. No decorrer da narrativa, entende-se que Joseph Seed também está vivo, e que cabe ao jogador resolver o destino dele e do restante do Portão do Éden.

Apesar de o Colapso ter acontecido de fato, a sociedade igualitária que Joseph concebia nunca pôde ser alcançada. O pretenso estado de homogeneidade que colocaria todos em pé de igualdade (e ele no topo), desempenhando funções sociais de forma harmônica, foi perturbado pelo fracasso iminente da a) ilusão de homogeneidade social e da b) ideia de mestre. Qualquer pretenso estado uniforme e harmonioso de um grupo social apresenta, por primazia, a afetação pelo "germe da disputa" (COSTA; LEANDRO-FERREIRA, 2019). Isto é, a relação de constante tensão que é constitutiva ao sujeito e que define, por excelência, a disputa inerente aos grupos assimétricos, síntese da luta de classes. Mesmo que o dinheiro não existisse como tal nesta nova comunidade, a ideia de acumulação e o princípio do lucro transformam a busca por recursos em trabalho e os materiais coletados em mercadoria, trocada por comida e água. Esses mesmos materiais também servem para fabricar armas improvisadas, de vez que a nova ameaça apresentada a essa comunidade, o "outro" necessário para defini-la como "um", está armado e pronto para saquear os bens acumulados. Uma vez mais, elementos como o desejo de pertencimento a um determinado grupo social que se afirma ao identificar um "inimigo" e o antagonismo entre esses agentes perpassam todo o organismo social, impedindo a totalização harmônica, concretização utópica, retorno ao Jardim Sagrado etc. 
De outro lado ainda, e mais precisamente sobre a ideia de mestre, o pensamento segundo o qual o homem domina natureza, se torna o senhor desse novo Éden, é baseado em uma relação dinâmica entre sujeito (o homem) e objeto (a natureza). A mesma dinâmica será replicada dentro da própria humanidade: de um lado, o sujeito que domina o processo de transformação da natureza e sua exploração pelo processo de produção; e de outro, o sujeito reduzido à função de objeto (os trabalhadores produtivos), aquele que paradoxalmente subordina a posição a que está subordinado. Sobre esse impasse, afirma Žižek, que "o meio de nos livrarmos de nossos senhores não é a humanidade se tornar um senhor coletivo sobre a natureza, mas reconhecer a impostura da própria noção de senhor" (ŽIŽEK, 2012, p. 198). A pergunta feita por Joseph em FC5, "esse é o mundo que construímos para nossas crianças? Comunidades divididas, muros enormes erguidos porque lideres são impotentes para agir, valentões confusos demais para liderar por justiça?", recebe um simpático "sim" como resposta em Far Cry New Dawn. E não necessariamente porque "cada escolha revela os nossos pecados" e estamos fadados a pagar por isso, como ele afirma; mas, sim, porque a criação de um novo regime não se encerra na obliteração do sistema anterior. A revolução não compreende apenas um "e se" alternativo da história que a procura revisitar ou reescrever, mas busca redimir as tentativas fracassadas do passado, admitindo, também, suas próprias inconsistências.

A ilusão de Joseph de que a sua visão é a mais correta dentre as dos homens e de que ela será o ponto de fratura que separa um estado de coisas de outro, convenientemente esquece de que existe um processo complexo pelo qual as estruturas sociais são formadas. Processo este que materialmente conecta o seu fundamentalismo religioso ao liberalismo que ele procura atacar. Por dessemelhantes que possam parecer nesse sentido, fundamentalismo e liberalismo integram uma mesma totalidade. O Total, como vimos, está longe de ser harmônico, funciona apenas como noção crítica que engloba as dissimetrias e antagonismos de um sistema em sua própria estrutura. É porque os princípios do fundamentalismo se opõem aos do liberalismo, que é possível dizer que o liberalismo produz o seu oposto; baseia-se numa rede de valores comunitários que ele mesmo destrói e que o fundamentalismo, em resposta, tenta resgatar.

Em 1982, ao apresentar a comunicação Ideologia: aprisionamento ou campo paradoxal (2012), Pêcheux aponta esse mesmo mecanismo de constituição responsiva sob a designação da relação entre o centro e as bordas de um sistema político. Nesse entorno, um ataque das bordas em direção ao centro perpassa uma série de encalços que o núcleo cria em torno de si para disfarçar a sua própria existência. Não existe forma de investida direta das bordas ao centro, e isso porque as bordas são elas mesmas decorrentes da ação ideológica desse centro estruturante cercado por aparelhos que visam garantir o seu bom funcionamento. Sobretudo, é preciso levar em consideração que é mais fácil que na tentativa de atingir o centro as bordas travem uma disputa interna fadada ao fracasso. Esse mecanismo baseado na criação de falsas-causas aponta, por exemplo, como ético-cultural um problema que é de natureza socioeconômica e que surge reprimindo essa dimensão constitutiva. Daí a complicação ideológica de dissimular a luta pela alteração do sistema econômico numa disputa religiosa e/ou ética, ou ainda, como no caso de Joseph, de encobrir um conflito subjetivo numa disputa de tipo político, fato que o próprio Pai reconhece nas cenas finais de New Dawn. 


\section{SOBRE O TOTALITARISMO: JOHN SEED E CARMINA RYE}

Se, no paralelo que foi tracejado no tópico anterior, Faith atuava na manutenção do aparelho religioso e Jacob representava as forças do aparelho repressivo; como advogado do Portão do Éden, John desempenha papel decisivo para o exercício do poder no aparelho jurídico. Na descrição oficial do jogo no site de FC5, John é apresentado como sendo aquele que "garante recursos vitais à sobrevivência do culto, seja isso uma casa ou uma pessoa", funcionando, assim, como a figura responsável pela arrecadação de fundos e aquisição das propriedades da seita: residências; igrejas; armas; rodoviárias; aeroportos; complexos; armazéns; e veículos terrestres e aéreos. Na prática, o fato de Hope County corresponder, em grande parte, ao acumulado das propriedades do Portão do Éden, justifica legalmente a liberdade de ação dos membros da seita. Salvaguardadas as devidas proporções, em FC5, John é a epítome da reprodução das condições materiais de existência do culto.

John sustenta a possibilidade de Joseph assumir um sentido de comunidade igualitária e autossustentável para o Portão de Éden. Num espaço deste tipo, a exemplo de Jonestwon, os membros podem trabalhar apenas pelo alimento da família, que perde a conotação local e passa a designar o próprio culto. A promessa é a de que a exploração da força de trabalho e a busca pelo engrandecimento pessoal, práticas particulares ao sistema capitalista liberal, cedam lugar ao trabalho comunitário e à alteridade absoluta, regida por um forte senso de solidariedade. Teoricamente, nesses meios não haveria comércio ou circulação de dinheiro, estando extinta a produção e venda de qualquer mercadoria. Dito de outra forma, os indícios materiais da dominação e da exploração do trabalhador são estranhos aos edenetes porque John legalmente detém as propriedades da seita e gerencia a distribuição de riqueza, sob o aval de fazer "isso sempre em favor do grupo, não do indivíduo”.

Não por acaso, a partir do ritual de "expiação", uma espécie de confissão dos pecados acompanhada da escarificação (por faca ou outra lâmina) do nome pelo qual estes são identificados (ira, gula, luxúria etc.) no corpo dos fiéis, John ataca diretamente a base sobre a qual se funda o senso de privacidade, tornando públicas as práticas "incorretas" cometidas em regime privado. Atacar a esfera privada é um passo fundamental para o processo de deturpação da ideia de posse, inclusive sobre o próprio corpo. Nesse sentido, pela doutrina imputada no ato de expiação, os corpos em comuna se entrelaçam em um único corpo e constituem, eles mesmos, a via direta para um despertar espiritual guiado pelo Pai. A proposta de John, dirigida ao jogador, "seja o seu pecado. Ele guia você, seus pensamentos, suas ações. Seu pecado é a ira. Torne-se a ira, deixe-a preencher o seu corpo e consumir sua alma, porque no fim você ainda será vazio", se concentra em incutir a ideia de que o sujeito, desde sempre fadado à danação, "é o que comete", coincide com o próprio pecado, e por isso se torna uma forma de existência desubstancializada e vazia. Ao operar essa despercepção, o sujeito se encontra reduzido a uma entidade espectral que é, ao mesmo tempo, invisível para os outros, mas observável para o Pai, que lança sobre o sujeito o olhar misericordioso de identificação e reconhecimento.

Essa mesma despercepção cerceia a fantasia utópica de FC5 que pressupõe para o Portão do Éden uma comunidade harmoniosa, isenta das disfunções que cerceiam a sociedade "pós-moderna". Nesse novo espaço, onde inexiste o homem moderno, cada 
um saberá organicamente a sua função e o seu lugar no mundo, operando em conjunto para a manutenção de uma sociedade que se propõe para "além-da-cultura", em sentido reverso: dentro do estado de natureza, refletido no modus operandi das abelhas em colmeia, por exemplo, em que a rainha corresponde ao próprio Joseph. A ilusão retroativa que situa o Éden como ponto zero da comunidade harmônica encobre o fato de que foi a própria queda, ou seja, a expulsão do homem do paraíso, o que tornou possível conceber a ideia de paraíso. O que a história repete nessa cadeia não é exatamente a tentativa de reconstrução do Jardim Sagrado (o que o Éden é), mas a sua queda (o que ele foi), que efetivamente continua a existir. Sobretudo em Far Cry New Dawn é possível perceber que o que se sabe sobre o Éden é que ele nos foi negado como tal, o paraíso só continua a existir como margem de impossível, de modo que toda tentativa de alcança-lo estaria fadada ao fracasso desde o princípio. Essa ideia se verifica, por exemplo, no começo da narrativa de New Dawn, quando Carmina Rye explica ao jogador como a humanidade conseguiu sobreviver depois do Colapso.

Em uma das missões principais de FC5, o jogador auxilia o pai de Carmina, Nick Rye, integrante das armas de aluguel (gun for hire), a levar sua esposa, que está prestes a dar à luz, até a casa da parteira de Hope County. Carmina, filha de Nick, nasce no mesmo ano em que ocorre o Colapso de FC5 e sobrevive abrigada em um bunker junto com a sua família e outros membros da resistência. Passado um rigoroso tempo de chuvas ácidas e fortes vendavais, 17 anos após as explosões nucleares, os humanos restantes começam a reconstruir a sociedade em que viviam. $O$ cenário do jogo, diferente do tom acinzentado que costumam apresentar as produções de narrativa pósapocalíptica, é de um colorido vívido, quase neon. Em Far Cry New Dawn, a natureza se ajustou à desordem causada pelas explosões e tomou posse das construções humanas, engolindo os prédios com arbustos floridos, cheios de animais cujas cores e formas foram afetadas pela radiação. Carmina descreve o espaço exterior como a coisa mais bonita que ela já viu, enquanto seus pais lamentam pela perda da sociedade como eles a conheciam.

Durante essa explicação fornecida por Camina também são apresentadas as antagonistas da nova história, as gêmeas Mickey e Lou, que comandam o grupo de Salteadores. Ao estilo de Mad Max, de James McCausland e George Miller, os salteadores constroem carros, armas e abrigos com os restos de matéria-prima e de etanol que conseguem encontrar pelo condado. A identidade visual dessas personagens e a trilha sonora que acompanha as cenas de história em que aparecem, mesclam elementos do grafite com a cultura da pichação, hip-hop, rap e trap music. A mistura dessas referências culturais modernas, objetiva promover a simpatia do jogador pelo grupo de salteadores. Como em outros títulos da franquia, a ideia não é meramente apontar um vilão radicalmente diferente, que pelo conjunto de seus atos perversos deve ser eliminado a qualquer custo; mas, sim, provocar algum tipo de reflexão no jogador, aproximando os divergentes e humanizando as figuras antagônicas. Assim que Mickey e Lou descobrem sobre a prosperidade do grupo de Carmina em Prosperity, os salteadores saqueiam os recursos coletados pela resistência, destruindo o vilarejo. É neste ponto que Carmina busca pela ajuda de um grupo de especialistas em sobrevivência e desenvolvimento, do qual o jogador é membro. No decorrer da narrativa, entende-se que Joseph Seed também está vivo, e que cabe ao jogador resolver o destino dele e do restante do Portão do Éden. 
Apesar de o Colapso ter acontecido de fato, a sociedade igualitária que Joseph concebia nunca pôde ser alcançada. O pretenso estado de homogeneidade que colocaria todos em pé de igualdade (e ele no topo), desempenhando funções sociais de forma harmônica, foi perturbado pelo fracasso iminente da a) ilusão de homogeneidade social e da b) ideia de mestre. Qualquer pretenso estado uniforme e harmonioso de um grupo social apresenta, por primazia, a afetação pelo "germe da disputa" (COSTA; LEANDRO-FERREIRA, 2019). Isto é, a relação de constante tensão que é constitutiva ao sujeito e que define, por excelência, a disputa inerente aos grupos assimétricos, síntese da luta de classes. Mesmo que o dinheiro não existisse como tal nesta nova comunidade, a ideia de acumulação e o princípio do lucro transformam a busca por recursos em trabalho e os materiais coletados em mercadoria, trocada por comida e água. Esses mesmos materiais também servem para fabricar armas improvisadas, de vez que a nova ameaça apresentada a essa comunidade, o "outro" necessário para defini-la como "um", está armado e pronto para saquear os bens acumulados. Uma vez mais, elementos como o desejo de pertencimento a um determinado grupo social que se afirma ao identificar um "inimigo" e o antagonismo entre esses agentes perpassam todo o organismo social, impedindo a totalização harmônica, concretização utópica, retorno ao Jardim Sagrado etc.

De outro lado ainda, e mais precisamente sobre a ideia de mestre, o pensamento segundo o qual o homem domina natureza, se torna o senhor desse novo Éden, é baseado em uma relação dinâmica entre sujeito (o homem) e objeto (a natureza). A mesma dinâmica será replicada dentro da própria humanidade: de um lado, o sujeito que domina o processo de transformação da natureza e sua exploração pelo processo de produção; e de outro, o sujeito reduzido à função de objeto (os trabalhadores produtivos), aquele que paradoxalmente subordina a posição a que está subordinado. Sobre esse impasse, afirma Žižek, que "o meio de nos livrarmos de nossos senhores não é a humanidade se tornar um senhor coletivo sobre a natureza, mas reconhecer a impostura da própria noção de senhor" (ŽIŽEK, 2012, p. 198). A pergunta feita por Joseph em FC5, "esse é o mundo que construímos para nossas crianças? Comunidades divididas, muros enormes erguidos porque lideres são impotentes para agir, valentões confusos demais para liderar por justiça?", recebe um simpático "sim" como resposta em Far Cry New Dawn. E não necessariamente porque "cada escolha revela os nossos pecados" e estamos fadados a pagar por isso, como ele afirma; mas, sim, porque a criação de um novo regime não se encerra na obliteração do sistema anterior. A revolução não compreende apenas um "e se" alternativo da história que a procura revisitar ou reescrever, mas busca redimir as tentativas fracassadas do passado, admitindo, também, suas próprias inconsistências.

A ilusão de Joseph de que a sua visão é a mais correta dentre as dos homens e de que ela será o ponto de fratura que separa um estado de coisas de outro, convenientemente esquece de que existe um processo complexo pelo qual as estruturas sociais são formadas. Processo este que materialmente conecta o seu fundamentalismo religioso ao liberalismo que ele procura atacar. Por dessemelhantes que possam parecer nesse sentido, fundamentalismo e liberalismo integram uma mesma totalidade. O Total, como vimos, está longe de ser harmônico, funciona apenas como noção crítica que engloba as dissimetrias e antagonismos de um sistema em sua própria estrutura. É porque os princípios do fundamentalismo se opõem aos do liberalismo, que é possível dizer que o liberalismo produz o seu oposto; baseia-se numa rede de valores 
comunitários que ele mesmo destrói e que o fundamentalismo, em resposta, tenta resgatar.

Em 1982, ao apresentar a comunicação Ideologia: aprisionamento ou campo paradoxal (2012), Pêcheux aponta esse mesmo mecanismo de constituição responsiva sob a designação da relação entre o centro e as bordas de um sistema político. Nesse entorno, um ataque das bordas em direção ao centro perpassa uma série de encalços que o núcleo cria em torno de si para disfarçar a sua própria existência. Não existe forma de investida direta das bordas ao centro, e isso porque as bordas são elas mesmas decorrentes da ação ideológica desse centro estruturante cercado por aparelhos que visam garantir o seu bom funcionamento. Sobretudo, é preciso levar em consideração que é mais fácil que na tentativa de atingir o centro as bordas travem uma disputa interna fadada ao fracasso. Esse mecanismo baseado na criação de falsas-causas aponta, por exemplo, como ético-cultural um problema que é de natureza socioeconômica e que surge reprimindo essa dimensão constitutiva. Daí a complicação ideológica de dissimular a luta pela alteração do sistema econômico numa disputa religiosa e/ou ética, ou ainda, como no caso de Joseph, de encobrir um conflito subjetivo numa disputa de tipo político, fato que o próprio Pai reconhece nas cenas finais de New Dawn.

\section{REFERÊNCIAS}

ALTHUSSER, Louis. Ideologia e aparelhos ideológicos do estado. Notas para uma investigação [1970]. In: ŽIŽEK, Slavoj (org.). Um mapa da ideologia. Tradução de Vera Ribeiro. Rio de Janeiro: Contraponto, 1996, p. 105-142.

BBC NEWS. 2 momentos em que Bolsonaro chamou covid-19 de 'gripezinha', o que agora nega. BBC News Brasil, 27 nov. 2020. Disponível em: http://bbc.in/3ns7oDb. Acesso em jan. 2021.

COSTA, Isaac; LEANDRO-FERREIRA, Maria Cristina. A violência constitutiva: relações entre pulsão de morte e expressões de luta no sujeito do discurso. Acta Scientiarum. Language and Culture, v. 41, 2019. Disponível em: https://doi.org/10.4025/actascilangcult.v41i2.46409. Acesso em: 23 abr. 2020.

DUNSMORE, Kevin. Ubisoft Discusses Far Cry 5's Bold New Setting, Potential Controversies, Lessons Learned. Hardcore Gamer, 2017. Disponível em: https://bit.ly/3alssEx. Acesso em abr. 2020.

FAR CRY 4. Dirigido por Alex Hutchinson, produzido por Dan Hay. Dunia Engine 2. Montreal: Ubisoft, 2014. Jogo eletrônico (XBOX 360).

FAR CRY Primal. Dirigido por Jean-Christophe Guyot, produzido por Vincent Pontbriand. Dunia Engine 2. Montreal: Ubisoft, 2016. Jogo eletrônico (PS4).

FAR CRY 5. Dirigido por Dan Hay, produzido por Darryl Long, escrito por Drew Holmes. Dunia Engine. Montreal: Ubisoft, 2018. Jogo eletrônico (PS4).

FAR CRY New Dawn. Dirigido por Jean-Sébastien Decant, escrito por James Nadiger. Dunia Engine. Montreal: Ubisoft, 2019. Jogo eletrônico (PS4).

FREIRE, Vinícius Torre. Baderna de Bolsonaro cresce muito mais que o PIB. Folha de São Paulo, 19 fev. 2020. Disponível em: http://bit.ly/3sbd9se. Acesso em jan. 2021.

MARX, Karl; ENGELS, Friedrich. A ideologia alemã: crítica da mais recente filosofia alemã em seus representantes Feuerbach, B. Bauer e Stirner, e do socialismo alemão em seus diferentes profetas [1845-1846]. Tradução de Rubens Enderle, Nélio Schneider, Luciano Cavini Martorano. São Paulo: Boitempo, 2007. 
ORLANDI, Eni. Entrevista com Eni Orlandi concedida ao Grupo Contradit. In: OLIVEIRA, Guilherme Adorno de; NOGUEIRA, Luciana (org.). Encontros na análise de discurso: efeitos de sentido entre continentes. Campinas: Editora da UNICAMP, 2019.

PÊCHEUX, Michel. Ideologia: aprisionamento ou campo paradoxal? [1982]. In: ORLANDI, Eni Puccinelli (org.). Análise de Discurso: Michel Pêcheux. 3. ed., Campinas: Pontes Editores, 2012.

PÊCHEUX, Michel. Semântica e discurso: Uma crítica à afirmação do óbvio [1975]. Tradução de Eni Puccinelli Orlandi, 5. ed. Campinas: Editora da UNICAMP, 2014.

VIGGIANO, Giuliana. Quem foi Charles Manson, o líder da seita que aterrorizou os EUA em 1969. Revista Galileu, 30 jul. 2019. Disponível em: http://glo.bo/3oxKFXD. Acesso em jan. 2021.

ŽIŽEK, Slavoj. Vivendo no fim dos tempos. Tradução de Maria Beatriz de Medina. São Paulo: Boitempo, 2012.

ŽIŽEK, Slavoj. Em defesa das causas perdidas. Tradução de Maria Beatriz de Medina. São Paulo: Boitempo, 2011.

Artigo recebido em: nov. de 2020.

Aprovado e revisado em: jan. de 2021.

Publicado em: fev. de 2021.

Para citar este texto:

COSTA, Isaac. A política do fim do mundo: Uma leitura discursiva de dois jogos da série "Far Cry". Entremeios [Revista de Estudos do Discurso, ISSN 2179-3514, on-line, www.entremeios.inf.br], Seção Estudos, Programa de Pós-Graduação em Ciências da Linguagem (PPGCL), Universidade do Vale do Sapucaí (UNIVÁS), Pouso Alegre (MG), vol. 23, p. 112-128, Edição especial/ 2020. DOI: http://dx.doi.org/10.20337/ISSN21793514revistaENTREMEIOSvol23pagina112a128 